\title{
REFORMA DA LEI DAS SOCIEDADES POR QUOTAS DE RESPONSABILIDADE LIMITADA *
}

\author{
PROF. RUBENS REQUIÃO
}

(Catedrático de Direito Comercial)

\section{Sociedade por Quotas de Responsabilidade Limitada Tipicidade de sua estrutura}

1 - É bem conhecida, por ser recente, a história das sociedades de responsabilidade limitada. Filiamo-nos entre os que atribuem o seu surgimento ao legislador germânico, que as introduziu no Código do Comércio de 1892.

A sociedade de responsabilidade limitada que ingressou no Direito brasileiro através do Decreto $n .^{\circ} 3.708$, de 10.1.1919, na verdade não se inspirou no Direito inglês como alguns autores supõem. Êsse direito, de fato, conheceu pelo Act de 1862 a sociedade chamada limited by garantee, na qual o capital podia ou não ser dividido em ações e em caso de liqüidação os sócios respondiam pelas dívidas sociais até o montante estipulado no contrato, e era comum proibir-se a cessão das ações. Êsse tipo de sociedade se pretendeu introduzir na França pela Lei de 1862, tendo vida efêmera, pois êsse diploma foi revogado em 1867, como veremos.

No Brasil imperial, o Ministro da Justiça Joaquim Nabuco, em 1865, tentou transplantá-la para o nosso Direito, partindo da lei francesa de 1863.

Chegou mesmo o Ministro a solicitar o parecer dos Tribunais de Comércio provinciais, apresentando-lhes um longo questionário, mas êsse desiderato foi frustrado pelo Conselho de Estado, que negou apoio à intenção ministerial.

A confusão criada nas origens históricas do instituto se deve ao fato de êsse tipo de sociedade no Direito francês ter sido denomi-

* Sugestões apresentadas ao Simpósio convocado, em Pôrto Alegre, pela Federação das Associações Comerciais do Rio Grande do Sul e pela. Associação Comercial de Pôrto Alegre. 
nado société à responsabilité limitée, denominação que Joaquim Nabuco vertera para o português literalmente.

2 - É interessante, para bem focalizar a finalidade econômica da nova sociedade, pesquisar as causas que determinaram a sua criação. Isso se deveu à preocupação simplificadora da estrutura e funcionamento das sociedades anônimas.

Todos sabem que na primeira metade do século passado as sociedades anônimas viveram sob o regime de autorização ou privilégio para sua fundação. O Estado mantinha duro contrôle sôbre os mesmos, não podendo ser elas livremente criadas.

A liberação das sociedades anônimas foi implantada na Inglaterra, nos meados do século passado, ficando os franceses inferiorizados em relação àquele país, sobretudo quando um acôrdo internacional permitia que as livres sociedades inglêsas operassem na França. Daí imaginar-se o artifício de, através de um esquema de simplificação, permitir-se a formação de nôvo tipo de sociedade anônima que escapasse à prévia autorização do Estado para constituir-se. Foi o que se pretendeu com a Lei de 1863; e tanto o episódio é verdadeiro, que tendo a nova Lei de 1867, sôbre sociedades anônimas, libertado a sua fundação da autorização da tutela do Estado, a société à responsabilité limités deixou de ter razão de existir, sendo porisso revogada a lei respectiva. O Professor WALDEMAR FERREIRA aborda êsse aspecto histórico, recorrendo às fontes francesas, esclarecendo: "No fundo, ainda tomando-se seus outros requisitos, dizia o expositor, aquela combinação não era mais do que o anonimato: mas o anonimato liberto do obstáculo que se the opunha à entrada - a autorização, l'anonymat libre ou peu s'en faut" vol. Iil, n. ${ }^{\circ}$ 522). THALLER, o prestigiado tratadista francês, esclarece que o regime instaurado pelo advento da Lei de 24.7.1867, ainda vigente em França até há pouco tempo, unificou o sistema e implantou a liberté reglamentée, isto é, estabeleceu para as sociedades anônimas o regime de estatuto de que resultou o desaparecimento da sociedade de responsabilidade limitada, por haver-se esvasiado seu objetivo.

Em síntese, quando foi dispensada a autorização, a nova sociedade anônima, simplificada, desapareceu da cena jurídica. Em 1882 nova lei no Brasil suspendeu, por sua vez, o vigorante regime de autorização prévia, reservando-a apenas para certos tipos de emprêsas, sistemas que perdura até a atualidade.

3 - Mas, mesmo no regime das sociedades anônimas livremente constituídas, ressentiam-se as emprêsas de médio porte de 
instrumento mais adequado, que permitisse o funcionamento mais expedito e sem os onerosos entraves de publicidade que 0 anonimato requer para a segurança do público.

Foram precisamente êsses os objetivos perseguidos pelo legislador alemão em 1892. Afastado o formalismo e o rigorismo publicitário, peculiar das sociedades anônimas, aligeirou-se o manejo da sociedade, na qual a responsabilidade dos sócios se resumia às entradas conferidas ou ao capital social. O Professor WALDEMAR FERREIRA, baseado em autor germânico, explica que objetivou com a nova sociedade "se rodeasse de maior simplicidade em sua constituição e desenvolvimento, de modo, e a observação é de KARL HEINSHEIMER, que servisse à emprêsa de ação restrita ou caráter provisório, especialmente às emprêsas de família". ("Tratado", vol. IV, pg. 388).

Êsse nôvo tipo foi em 1901 introduzido no direito português, segundo o modêlo da lei alemã, onde o Professor INGLEZ DE SOUZA foi buscar elementos para transpo-lo, em 1912, para o seu Anteprojeto de Código Comercial. A Exposição de Motivos dêsse Anteprojeto exaltava a excelência da sociedade proposta, a qual se prestava, segundo o autor, "a animar a concorrência das atividades e dos capitais ao comércio, sem ser preciso recorrer à sociedade anônima que melhor se reservará para as grandes emprêsas industriais, que necessitam capitais muito avultados e prazo superior ao ordinário da vida humana" (ob. cit. pg. 24). Dêsse Projeto, como todos sabem, surgiu a Lei de 1919.

4 - Tendo em vista todos êsses fatôres e pressupostos históricos e técnicos, sustentamos que as sociedades de responsabilidade limitada devem permanecer no Direito brasileiro com a função para a qual foram criadas, isto é, de atender à estrutura técnica e jurídica das emprêsas de pequeno e médio porte, que modernamente são conhecidas como "sociedades fechadas" ou "sociedades de família". Sua qualificação deve permanecer como sociedade de pessoas que é a tradição que a melhor doułrina instituiu.

Essa sociedade se forma, ao nosso entender, pelo contrato plurilateral, que restringe a responsabilidade dos sócios até 0 montante do capital social. As quotas não constituem valôres mobiliários, e é, como veremos, universal o princípio de que as quotas não devem ser representadas por títulos negociáveis. (RAUL VENTURA, Cessão de Quotas, pg. 6.)

Em conseqüência, as quotas não devem ser corporificadas em 
"títulos valôres" ou títulos de crédito representativos do seu valor e documento de legitimação do stałus de sócio.

Devemos, pois, manter-nos fiéis à natureza dessa sociedade, tendo em vista, inclusive, as lições do Direito Comparado. As antigas e as recentes legislações, vedam que a sociedade emita títulos mobiliários, como passamos a verificar:

A Lei alemã de 1892, no artigo 15, alín̨ea $3 .^{a}$ dispõe:

"As partes sociais não podem ser cedidas senão por contrato passado sob forma judiciária ou notarial". O Código Civil italiano, no art. 2472, prevê: "As quotas de participação dos sócios não podem ser representadas por ações".

A Lei francesa de 1966, reza:

"Sob pena de nulidade da emissão, é interdito a uma sociedade de responsabilidade limitada emitir valôres mobiliários". O Código de Obrigações suíço no art. 722, estabelece: "Todo sócio participa do Capital Social sem que sua parte (parte social) tenha o caráter de ação."

A Lei Geral de Sociedades Mercantis, do México, de 1933 no artigo 58, registra:

"Sociedade de responsabilidade limitada é a que se constitui entre sócios, que sòmente estão obrigados ao pagamento de sua contribuição sem que as partes sociais possam estar representadas por títulos negociáveis, à ordem ou ao portador, pois só serão cessíveis nos casos e com os requisitos que estabelece a presente lei."

A Lei de Portugal, que se seguiu em 1901 à Lei alemã, dispõe no art. 6, que as quotas sociais são transmissíveis nos têrmos de direito e a cessão deve constar de documento autêntico. A Lei brasileira de 1919, nada dispõe sôbre o assunto, pois, supomos, a ninguém podia ocorrer fôsse possível a representação da quota em título negociável, tendo em vista que a negociabilidade das partes do capital representadas em ações é típica das sociedades anônimas.

Em conclusão, sustentamos:

$1 .^{\circ}$ - que a tentativa histórica de simplificação das sociedades anônimas resultou frustrada;

$2 .^{\circ}$ - que a sociedade por quotas de responsabilidade limitada, do direito atual, constitui um tipo intei- 
ramente nôvo de sociedade, criado pelo legislador, e assim deve ser tratada;

3. ${ }^{\circ}$ - que a sociedade limitada, em princípio, se destina às emprêsas de médio porte e às sociedades familiares ou fechadas, já que as sociedades anônimas estruturam as grandes emprêsas de capitais.

\section{Transferência de Quotas}

1 - Na reelaboração do direito societário, relativo às sociedades por quotas de responsabilidade, não se deve perder de vista que constituem elas um tipo peculiar, não se devendo considerá-las ou thes dar o tratamento de sociedade anônima simplificada. Em outro estudo correlato demonstramos que a História registra o abandono da idéia de sociedades anônimas simplificadas, ocorrida na França em 1863.

Ora, no instante em que a sociedade por quotas fôr considerada sociedade anônima simplificada, decreta-se-lhe a morte. E não é conveniente o desaparecimento de um tipo de sociedade que tanta utilidade tem no mundo jurídico e no mundo dos negócios.

Dentro da estrutura personalista dessa sociedade pode-se, perfeitamente, sem provocar a sua desfiguração, adaptá-la melhor aos fins a que é destinada, isto é, dar o suporte jurídico às emprêsas familiares ou de pequeno e médio porte.

Uma das críticas que se faz às sociedades por quotas, na sua configuração atual, é a forma arcaica e inconveniente de cessão e transferência das quotas. Qualquer retirada ou ingresso de sócio importa na modificação do contrato social, inconveniente que não necessita de maior análise.

Ora, o processo de cessão e transferência de quotas pode ser simplificado, ou se the dar uma nova técnica, que assegurando os interêsses da sociedade e dos credores, permita mais fácil acesso ou retirada do quadro social.

Aventou-se a idéia de que a sociedade fôsse legalmente dotada de um livro de "Registro de Quotas" onde as cessões ou transferências seriam averbadas. A sociedade requeria, em conseqüência, obrigatòriamente ao registro do comércio o arquivamento de cópia autêntica do têrmo que valerá como instrumento de alteração contratual.

Em princípio é válida a idéia. A sociedade, pelo sistema indi- 
cado, poderia fiscalizar a regularidade da cessão e transferência, caso no contrato houvesse cláusula de preferência dos antigos sócios na aquisição da quota do sócio retirante ou de necessária anuência da admissibilidade do sócio que ingressa.

O que tememos, porém, é que a sociedade, por seu representante legal, não efetue a averbação no Registro do Comércio do têrmo de transferência ou cessão lavrado no livro de registro de quotas. Essa omissão poderia ser involuntária, proveniente de desídia, mas também poderia ser maliciosa, prejudicando o sócio que pretendeu retirar-se da sociedade, mas cuja retirada não se consumou em relação a terceiros.

Para afastar êsse inconveniente poder-se-ia estabelecer que 0 contrało de cessão de quotas fôsse levado à inscrição no Registro do Comércio, após o que, sòmente então, se faria a sua averbação no livro competente da sociedade. A validade do contrato de cessão ou transferência da quota surgiria sòmente após a averbação do contrato no livro próprio da sociedade.

\section{Penhorabilidade das Quotas das Sociedades por Quotas de Responsabilidade Limitada}

1 - Constitui regra processual que as quotas das sociedades comerciais não são objeto de penhora. Assim, com efeito, dispõe o Código de Processo Civil, a saber:

Art. 942 - Não poderão absolutamente ser penhorados:

XII - Os fundos sociais, pelas dívidas particulares dos sócios, não compreendendo a isenção os lucros líqüidos verificados em balanço.

Art. 943 - Poderão ser penhorados, à falta de outros bens:

II - Os fundos líquiidos que possuir o executado em sociedade comercial.

A norma processual reflete o preceito do art. 292 do Código Comercial que determina:

“O credor particular de um sócio só pode executar os fundos líquiidos que o devedor possuir na companhia ou sociedade, não tendo êste outros bens desembargados, ou se, depois de executados, os que tiver não forem suficientes para o pagamento.' 
2. A razão dessas normas processuais decorre do princípio consagrado no Direito Brasileiro, de que as sociedades comerciais regularmente registradas adquirem personalidade jurídica. Impressionados, portanto, com a autonomia patrimonial decorrente dessa personificação, os processualistas levaram o princípio às últimas conseqüências: a quota do capital subscrita e integralizada pelo sócio, não responde pelas suas dívidas particulares.

A jurisprudência dos tribunais tem considerado impenhorável a quota do sócio nas sociedades por quotas de responsabilidade limitada, tendo todavia o Supremo Tribunal Federal distinguido: se no contrato social houver cláusula permissiva da transferência da quota independente da prévia anuência dos demais sócios, torna-se viável a penhora; caso contrário, se o ingresso de nôvo sócio depender do assentimento dos demais sócios, a quota é impenhorável.

O Projeto de Código de Processo Civil não repete o preceito do Código vigente, mas o Projeto de Código de Obrigações (Projeto n. ${ }^{\circ}$ 3.264 , de 1965) no artigo 1.163, dispõe entretanto:

"O credor particular de sócio pode, na insuficiência de outros bens do devedor, fazer recair a execução sôbre o que a êste couber nos lucros da sociedade ou na parte que the tocar em liqüidação.

Parágrafo único. Se a sociedade não estiver dissolvida, pode o credor requerer a liqüidação da quota do devedor, cujo valor, apurado na forma do art. 1.168, será depositado em dinheiro, no juízo da execução, até três mêses após a liqüidação".

3. Estudando o importante tema - se a cláusula que dispõe sôbre a intransferibilidade impede a impenhorabilidade da quota - Professor RAUL VENTURA, Catedrático da Faculdade de Direito de Lisboa, na sua monografia "Cessão de Quotas", comenta:... "não pode conceber-se que uma pessoa coloque todo o seu patrimônio ao abrigo da execução dos credores, transformando todo êle (salvo exceções relevantes) em quotas de sociedades: não pode admitir-se que um pacto entre certas pessoas produza efeitos relativamente a estranhos, restringindo ou até eliminando direitos dêstes provenientes de atos com os quais aquêles nenhuma relação possuem".

No direito comparado, deparamo-nos com a doutrina alemã no sentido da ineficácia de cláusula de intransmissibilidade ou da cláusula de consentimento, quando se trata de transmissão forçada, doutrina também adotada pelos juristas austríacos. 
No direito italiano, o art. 2.480, alínea $3 .{ }^{a}$, do Código Civil, estabeleceu que se a quota é livremente transferível e o credor, o devedor e a sociedade não se põem de acôrdo, sôbre a venda da quota, essa pode realizar-se em leilão, mas a venda fica sem efeito se, nos dez dias seguintes à adjudicação, a sociedade apresentar outro adquirente que ofereça o mesmo preço.

4. O sistema preconizado no Projeto de Código de Obrigações, reproduzido acima, é pernicioso para o credor. Sujeita-o, além da ação ordinária e sua execução de sentença, se fôr o caso, a um outro processo - que é o da liqüidação da quota do devedor na sociedade de que seja sócio.

Sabemos que a lei procesual deve o quanto possível simplificar - processo. O dispositivo indicado, no Projeto de Código de Obrigações, levaria justamente ao contrário, complicando o ressarcimento do credor.

Em face do exposto, sugerimos que se estabeleça no direito brasileiro o sistema da plena penhorabilidade das quotas, mesmo que o contrato social consagre sua intransmissibilidade ou submeta a sua cessão à anuência prévia dos demais sócios.

Penhorada a quota, levada a leilão, a sociedade ou os sócios, devem ter o direito de preferência ao licitante que melhor lance oferecer, adjudicando a quota, desde que usem dêsse direito dentro de 5 dias, com o depósito do valor da arrematação. Se tal direito não for exercitado, o arrematante pode ingressar na sociedade como sócio detentor da quota arrematada.

\section{Assembléia Geral das Sociedades por Quotas de Responsabilidade Limitada}

1. A assembléia geral nas sociedades comerciais se justifica pela necessidade de se reunirem os sócios, desconhecidos e dispersos, para determinarem a política da emprêsa, para elegerem os diretores e fiscais e para tomarem as contas da diretoria.

A evolução, porém, das sociedades anônimas, o absenteísmo dos acionistas nas reuniões e assembléias gerais, a "grande maioria silenciosa" das sociedades anônimas, constitui hoje um fato que nenhum jurista desconhece ou esconde. Escreveram com ênfase - BERLE \& MEANS - na sua famosa obra "The Modern Corporation and Private 
Properfy", - que "o voto dia a dia perde a sua importância". Com a ampliação dos podêres do "Conselho de Administração" esmaecem-se os podêres das Assembléias Gerais.

O que se vê, em nosso país, confere perfeitamente com as observações dos autores. Os acionistas, na maioria, são apenas investidores, interessados ou na cotação das ações na Bôlsa ou interessados no resultado final do balanço anual para colherem os dividendos. Daí a classificação moderna dos acionisłas em acionistas-empresários, acionistas-especuladores e acionistas-rendeiros, quer se interessem pelo fortabelecimento da emprêsa, pela cotação de seus investimentos ou pela renda de seus investimentos.

2. Ora, se tal fenômeno ocorre nas sociedades anônimas, nas quais se torna imprescindível a constituição dos acionistas em assembléia geral, atuando esta como órgão da sociedade, não se deve em nosso entendimento - tornar obrigatória nas sociedades por quotas limitadas a reunião dos sócios em assembléia geral. Nas próprias sociedades anônimas pequenas e médias, nas sociedades fechadas ou de família, na imensa maioria das vêzes, a assembléia geral, como iodos sabem, se reúne simbòlicamente, para preencher uma exigência legal. As convocações são feitas legalmente, mas no dia da reunião não comparecem os acionistas, que assinam posteriormente, em seus domicílios, a ata. As reuniões se efetivam, nesse setor das sociedades fechadas ou de família, quando surgem divergência e aparecem os sócios dissidentes.

Parece-nos, pois, destituída de maior senso a idéia de tornar compulsória, instituir-se como obrigação legal, a reunião anual dos sócios quotistas em assembléia geral.

Se desejamos simplificar o funcionamento das sociedades comerciais, ajustando-as melhor às condições técnicas imperantes e à realidade social dominante no seu quadro de sócios, não se deve complicar o funcionamento da sociedade por quotas de responsabilidade limitada, cujo surgimento foi precisamente aligeirar o funcionamento das sociedades anônimas, tão burocratizadas pelo direito moderno.

3. Examinemos, por exemplo, o Projeto de Código de Obrigações (Projeto n. ${ }^{\circ} 3.264$, de 1965). Ali instituiu-se como compulsória a reunião dos sócios em asembléia geral, para deliberarem sôbre diversos atos, tais como a aprovação das contas da administração, a designação dos administradores, quando feita em ato separado; a destituição dos administradores, o modo de sua remuneração quando não 
estabelecido no contrato, a modificação do contrato social; a incorporação, a fusão e a dissolução da sociedade; a nomeação e destituição dos liqüidantes e o julgamento de suas contas, o pedido de concordata, ou a cessação da liqüidação da sociedade, conforme reza o art. 1.202.

Mas, essa formalidade da assembléia geral é dispensável, quando todos os sócios sufragam, por escrito, a mesma decisão, sôbre a matéria que dela seria objeto. E, ao mesmo tempo, o Projeto dispensa a convocação quando todos os sócios compareçam ou se declarem, por escrito, cientes do local, data, hora e ordem do dia.

4. Não seria mais prudente, mais funcional e mais lógico que se invertessem os termos da equação, deixando aos sócios a faculdade de instituir, no pacto social, a necessidade da assembléia geral? Por que modificar-se a tradição de nosso direito no que concerne às sociedades limitadas, as quais na sua imensa maioria, em nosso país, dispensam nos seus contratos a reunião dos sócios? A maioria dêsse tipo de sociedade, em nosso país, é constituída de dois ou três sócios, não existindo muitas com mais de 10 sócios. Compreende-se, por ventura, que uma sociedade de corpo social tão exíguo tenha que atender à exigência de reunião de assembléia geral, com registro de livros competentes com lavratura e registro de atas?

O irrealismo da proposição, impugnada, leva à não menos irrealista sugestão de se estabelecer a obrigatoriedade da assembléia geral apenas para as sociedades com mais de cinco sócios. Então teríamos o sistema de duas espécies de sociedades por quotas: as "pequenas" sociedades, com menos de cinco sócios, dispensadas da assembléia geral, e as "grandes" sociedades limitadas, com mais de cinco sócios, para as quais seria exigida a reunião anual dos sócios.

No momento em que as emprêsas sustentam a necessidade de simplificar e desburocratizar as sociedades anônimas, constitui gritante non sense, complicar o funcionamento das sociedades por quotas de responsabilidade limitada.

Por conseguinte, sugerimos que as sociedades por quotas limitadas poderão instituir, facultativamente, no respectivo contrato social, a obrigatória reunião dos sócios em assembléia geral para deliberação sôbre os assuntos que indicar; não dispondo o contrato social sôbre o modo de convocação e funcionamento da assembléia geral, aplicam-se subsidiàriamente os preceitos das sociedades anônimas. 


\section{Efeiłos da Tribułação e seu Reflexo nas Sociedades por Quołas de Responsabiildade Limitada}

1. A sociedade de responsabilidade limitada, em nosso país, objetivou como nos demais países em que foi implantada, a constituição das médias emprêsas, cuja estrutura econômica não comporte - complicado e oneroso dispositivo de constituição e funcionamento necessários às sociedades anônimas. Foram incluídas, pois, entre as sociedades de pessoas, já que as quotas tomadas pelos sócios não se representam em "títulos valôres", como as ações e se veda geralmente a sua cessão a terceiros, sem o consentimento expresso dos demais sócios.

Um fato bem conhecido e já suficientemente discutido não permitiu, todavia, o pleno sucesso da disseminação dêsse tipo nôvo de sociedade nos meios comerciais de nosso país.

Deve-se essa circunstância ao fato de, poucos anos após a promulgação da Lei $n .^{\circ} 3.708$, que instituiu as sociedades de responsabilidade limitada no Direito brasileiro, ter sido por sua vez criado o Impôsto de Renda, visando sobretudo aos lucros das emprêsas mercantis. E antes que a sociedade de responsabilidade limitada se impusesse à confiança do empresariado nacional, os empresários mais argutos perceberam as vantagens que $\circ$ anonimato representava, em face da avassaladora volúpia tributária que se apossou da administração pública.

As ações ao portador constituíam, como é facil de compreender, um cômodo instrumento para a evasão tributária, não só do Impôsto de Renda, como do impôsto causa mortis, no caso de falecimento do sócio.

Em inúmeras ocasiões atribuímos a desmedida simpatia dos pequenos e médios empresários nacionais pelo tipo de sociedade anônima, para configurar jurìdicamente suas emprêsas, à má orientação da política tributária de governos passados, nas décadas de 1930 a 1960.

Em 1958 movimentou-se o Govêrno, através de seu Ministro da Fazenda, Professor SAN TIAGO DANTAS, para coibir a evasão fiscal através das ações ao portador, propondo a extinção dessa forma de ações. Pudemos nessa ocasião opinar sôbre o projeto governamental da extinção das ações ao portador, considerando-as válvula de evasão ponderável de tributos e sua utilidade para encobrir a penetração de capitais estrangeiros. Não deixamos de reconhecer na ocasião que 
"o anonimato proporciona um excepcional tratamento tributário para os acionistas", e lembrávamos os seguintes aspectos tributários: a imunidade fiscal do ágio relativo à venda das ações acima do valor nominal; imunidade absoluta do impôsto de transmissão causa moris; favorecimento dos acionistas de altos dividendos, pela limitação da incidência do impôsto de renda na fonte, sem repercussão na declaração do impôsto complementar progressivo da pessoa física." (Rev. de Dir. Mercantil, vol. III, pg. 42).

Aliás, TULIO ASCARELLI, quando no Brasil, percebeu êsse problema, tendo escrito em sua conhecida obra que "na sociedade anônima familiar a forma ao portador das ações, quando adotada, o é mais por considerações de natureza fiscal do que no intento de facilitar a circulação". (Problemas das S. A. e Direito Comparado, dg. 33).

Não gozando e nem proporcionando tais vantagens, é claro que as sociedades limitadas cederam seu lugar às sociedade anônimas na organização jurídica das emprêsas de pequeno e médio porte, tornando-se por via de conseqüência as sociedades anônimas o mais popular e usado tipo de sociedade comercial no Brasil.

2. Das três vantagens tributárias acima enumeradas, temos a considerar que algumas delas foram extintas, em virtude da reforma do Sistema Tributário Nacional. O impôsto causa mortis não alcança mais os valôres mobiliários, e portanto as ações como partes de capital não ensejam o lançamento tributário; as autoridades fazendárias recentemente equipararam o ágio na venda de quotas de sociedade limitada ao da venda das ações, para considerar um e outro imune ao Impôsto de Renda. Resta a terceira vantagem, que ainda perdura a favor das ações ao portador. Persiste ainda o privilégio tributário das ações ao portador, pois o Regulamento do Impôsto de Renda limita em 25\% a tributação dos dividendos das ações ao portador "na fonte", sem repercussões na declaração da pessoa física do acionista, e na sociedade anônima de capital aberto a alíquota se limita a 15\%. Posteriormente, estendeu-se o mesmo favor às ações nominativas. E, no entanto, a lei fiscal não favorece as sociedades de responsabilidade limitada, cujos lucros distribuídos repercutem fundamente no impôsto progressivo da pessoa física.

Compreende-se porque o Govêrno favoreceu tributàriamente as ações das sociedades anônimas. Com êsse favor, criou-se um incentivo fiscal poderoso para atrair o interêsse de investidores que passaram a aplicar seus cabedais em títulos acionários, vitalizando-se ponderàvelmente com isso o mercado de capitais, com o fortalecimento das emprêsas. Mas se deve compreender também, que o desenvolvi- 
mento nacional se processa, em expressivo setor, pelas sociedades de responsabilidade limitada. Não há razão, pois, para que o estímulo investidor atinja apenas as sociedades anônimas desconhecendo as sociedades limitadas.

Já está assentada a idéia, na consciência empresarial e jurídica dos técnicos, que a disseminação das sociedades anônimas, no meio do pequeno e médio empresariado, constitui nas mais das vêzes um elemento de desmoralização para os títulos acionários pelos gravíssimos problemas criados em face do indisfarçável personalismo dessas pequenas e médias emprêsas. Êsses problemas, decorrentes dos abusos que cotidianamente se presenciam no âmbito das sociedades "fechadas", com o sacrifício das minorias na percepção dos dividendos, está a clamar por uma solução.

Estamos firmemente convencidos de que seria da maior utilidade para a restauração de um sadio e próspero mercado de capitais no País, que se desestimulasse a permanência das pequenas e médias sociedades anônimas, encaminhando-as para a tipicidade das sociedades limitadas. A conversão assim verificada, resultaria em ponderável economia para essas pequenas e médias emprêsas, que não teriam anualmente as expressivas e custosas despesas com a publicação dos atos sociais, aligeirando-se o seu funcionamento através das sociedades de responsabilidade limitada.

Para isso, ao nosso ver, bastaria que o Govêrno outorgasse, na Legislação do Impsôto de Renda, às quotas, o mesmo favorecimento tributário que hoje dispensa às ações das sociedades anônimas, instituindo-se facultativamente para o sócio das limitadas o recolhimento do Impôsto de Renda na fonte, mediante a mesma alíquota concedida às ações das sociedades anônimas fechadas, isto é, vinte e cinco por cento do dividendo percebido. Após isso, assistiríamos o rápido processo de conversão das médias emprêsas hoje anônimas em sociedades limitadas, com grande efeito para o saneamento do mercado de capitais no setor acionário. 